\title{
A paradox of alliance management: resource contamination in the recorded music industry
}

\author{
JONATHAN GANDER ${ }^{1}{ }^{\dagger}$, ADRIAN HABERBERG ${ }^{2}$ AND ALISON RIEPLE ${ }^{2}$ \\ ${ }^{1}$ University of East London, U.K. \\ ${ }^{2}$ University of Westminster, London, U.K.
}

Summary

\begin{abstract}
This paper deals with the problem of resource contamination in alliances, where incompatible resources may be transferred into or accessed by partner firms, thereby devaluing their own resources. Theory explains how collaborations between organizations can allow mutually beneficial resource combinations through the transfer of, or access to, the assets and/or capabilities of each partner. Research has focused on how to facilitate intended resource transfer while limiting unplanned appropriation of other resources. Here, we address how organizations can protect themselves from contamination by their partners. Resource inimicality arises from idiosyncratic path-dependent processes that create organizations with very different skills, assets and institutions. Thus, a paradox emerges where resources that are complementary may nonetheless be hostile if brought together in one firm: the exposure of one partner to another may erode the distinctive properties that make the partnership valuable. This paper explores this resource contamination perspective using interview data from managers of one Major music company and several smaller Independent partners. In this industry it is common for collaborations to occur between organizations whose resources are focused on the identification and creation of new artistic products, and partners whose resources exploit such products. These resources are complementary but also potentially hostile. We discuss the role of institutional structures and boundary spanners, individuals who mediate resource transfer across the organizations' boundaries, in resolving this paradox and inhibiting contamination. Copyright (C) 2007 John Wiley \& Sons, Ltd.
\end{abstract}

\section{Introduction}

Since the development of the resource-based view (RBV) of the firm (Barney, 1991; Penrose, 1959; Peteraf \& Barney, 2003; Wernerfelt, 1984), organizational resources have enjoyed a privileged position in the iconography of strategic management. A substantial body of theory has grown up to show how, in favorable habitats - the organizations in which they develop - they can become sources of enduring advantage. Resources are assets, positive attributes of an organization; the word 'resource' carries comforting connotations of support in adversity. Since resources develop in an idiosyncratic,

\footnotetext{
* Correspondence to: Jonathan Gander, University of East London, Docklands Campus, University Way, E16 2RD, U.K. E-mail: j.gander@uel.ac.uk

${ }^{\dagger}$ The authors are listed in alphabetical order to recognize the equal contribution each made to the writing of this paper.
} 
path-dependent manner (Nelson \& Winter, 1982; Reed \& DeFillipi, 1990), they are sensitive to context and so difficult to transplant. This, indeed, is the basis of their strategic value, the only downside being, if a resource ends up in an inappropriate environment its value might be diminished or destroyed.

Less attention has been paid, however, to the potential consequences for the host environment should an inappropriate resource enter it. In his seminal article Wernerfelt (1984) hinted at the possibility that resources might have a darker side, and there is some evidence for this from studies in corporate-level strategy. Campbell, Goold, and Alexander (1995) showed how the resources of the corporate parent can, under certain circumstances, actually damage subsidiaries. We argue that this generally neglected aspect of the RBV is a particular problem in alliances.

The term 'alliance' spans a wide variety of inter-organizational relationships with varying legal forms and levels of reciprocal investment. They encompass technology development projects, distribution and licensing agreements and more flexible support provision (promotion and sales), in which benefits sought include the reaching of newly opened markets (Lei \& Slocum, 1991); responding to an increasingly competitive and global environment (Faulkner, 1995); as vehicles for learning (Hamel, 1991; Senge, 1992); and as a way of spreading risk (Porter \& Fuller, 1986). Through alliances, firms achieve synergistic benefits by bringing together diverse resource sets (Das \& Teng, 2000a; Powell, 1987). However, the difficulties involved in transferring resources across organizational boundaries (Cohen \& Levinthal, 1990; Mowery, Oxley, \& Silverman, 1996; Von Hippel, 1994) render alliances prone to instability resulting from, inter alia, incompatible goals and lack of co-operation between entities with divergent cultures (Das \& Teng, 2000b; Gill \& Butler, 2003). Inequality in power is also likely to be a factor, although this has not yet featured strongly in empirical research on alliances. Power asymmetry may be based on, for example unequal shares of equity in joint ventures (Blodgett, 1992), the relative importance of the venture to the partner (Harrigan \& Newman, 1990) and uneven resource contributions (Bacharach \& Lawler, 1980; Hamel, 1991). This latter factor is a dynamic one as resources are transferred and used unevenly and asynchronously, becoming more or less important to the partner over time to such an extent that in extreme cases a firm can eliminate its dependence on a partner entirely (Inkpen \& Beamish, 1997).

It is clear that existing theories of alliance formation can explain the prevalence of relationships between firms in the recorded music industry, including our sample of those between a Major and its Independent partners, but not necessarily their success. We believe that resource contamination may also be a factor in alliance instability. Thus, in order to better understand the performance and persistence of these alliances, we argue for the introduction of a resource-preservation perspective, where the organizing principle is to not only protect collaborators' resources from capture but also shield those resources from institutionally hostile practices, policies and cultures in partner firms. Thus the task of alliance managers is to deal with the paradox whereby the exposure of one partner to another may simultaneously erode the distinctive properties that make the partnership valuable.

In our sample, none of the partners was preoccupied with the potential loss of their own resources and there was no evidence of the learning races mentioned in the alliance literature. Yet the smaller firms still took great pains to keep their distance from their larger partners and the managers from the large corporation, for their part, seemed content to accede in this. In the remainder of this paper we explore some of the reasons why we believe this illustrates an important feature of alliances.

\section{Theories of Resource Management in Alliances}

The resource- and knowledge-based views of the firm (Barney, 1991; Grant \& Baden-Fuller, 1995, 2004; Penrose, 1959; Spender, 1996; Wernerfelt, 1984), argue that organizational advantage is 
achieved through the effective acquisition and utilization of valuable resources. A resource is 'an asset or input to production (tangible or intangible) that an organization owns, controls or has access to on a semi-permanent basis' (Helfat \& Peteraf, 2003: 999). If its contribution to competitive advantage is not to be 'traded away' by an observant competitor, it must be valuable, rare, imperfectly substitutable and imperfectly inimitable (Barney, 1991).

When organizations agree to collaborate, the potential problem arises that partners may use the alliance to capture or copy pooled, competitively valuable resources (Balakrishnan \& Koza, 1993). Writers on alliances identify two responses to this. Organizations may begin a learning race (Kale, Singh, \& Perlmutter, 2000), attempting quickly to learn as much as possible before terminating the alliance; 'exposure' to a partner firm is minimized and the possibility of resource appropriation reduced. Alternatively, partners draw up legal and procedural barriers to manage the flow of resources between them (Hennart, Roehl, \& Zietlow, 1999), setting the boundaries of the firm according to their desired permeability: which resources are permitted to pass between the firms and which are not (Borys \& Jemison, 1989; Spekman, Forbes, Isabella, \& Macavoy, 1998).

\section{Inimical resources}

This paper extends the theory of the management of knowledge-based resources in collaborations, contending that partners' resources need to be safeguarded not only against appropriation but also against contamination. Our argument is that certain inimical resources, if transferred into or accessed by either partner firm, prevent or degrade the functioning of existing resources or routines. Inimical resources only become so when transferred into specific contexts that make their effects harmful. For example if routines that emphasize efficiency are introduced into a context that has previously focused on innovation and responsiveness, competitiveness may be degraded. This occurred at Novotel, an international hotel firm, which obtained a competitive advantage through the standardization of design and some operational routines, so that guests encountered dependable levels of décor and comfort. However, the expansion of these standardized routines to the hospitality function limited staff's ability to respond warmly to guests, or respond to the local competitive environment; it has since been rescinded (Baden-Fuller, Hunt, \& Calori, 1995).

The effectiveness with which organizations deploy and access resources is thus a contingent outcome of how they are used (Bhaskar, 1978; Penrose, 1959). This, in turn, is dictated by situationally specific factors such as organizational structures, networks of relational contracts, social conventions, ideology and culture (Amit \& Schoemaker, 1993; Emirbayer, 1997; Fiol, 1991; Granovetter, 1985; Storper, 1997; Venkatraman \& Subramanian, 2002). Such factors potentially both constrain and equip an organization by providing access to valuable resources and the ability to exercise them effectively (McEvily \& Marcus, 2005). We argue that the introduction, via an alliance partner, of new resources or changes to the organization's situationally specific features, can effectively contaminate its existing resources by altering their capacity to deliver the required benefits.

These situationally specific factors we define as catalytic resources - features which are themselves inert, but which act as catalysts on other resources to bring about or hasten a result. For example a supportive culture can encourage knowledge sharing. While catalytic resources are not transferable, elements of them such as organizational scripts (Barley \& Tolbert, 1997; Gioia \& Poole, 1984) are (Burns \& Stalker, 1961). These elements, which we term 'resource particles' may wither without the enabling effect of situationally specific catalytic resources, or may actually contaminate the resources of the partner. For example, for many years, new recruits to Amazon.com were given a door from which to construct their desk (Hill \& Jones, 2001). This had both symbolic and motivating effects: it indicated the importance of parsimony, instilled a sense of belonging and acted as a reminder of the company's 
'difference'. While this practice (a resource particle) could be transferred elsewhere, it would seem out of place without Amazon's catalytic resources, such as its ideology of celebrating 'otherness', which gave it meaning.

We suggest that there are likely to be two main effects of contamination through the transfer of inimical resources. First, processes (existing and planned) fail to function or operating routines become less effective. Numerous examples of problems between new venture divisions and their parent/ partners can be found in the innovation literature. For example Kodak's head office, despite its intentions of allowing procedural autonomy to its new product development divisions, which had been set up with the explicit aim of encouraging innovation (Simon, Houghton, \& Gurney, 1999), appears not to have been able to stop itself from imposing its own routines on its divisions. As a result the entrepreneurial spirit that it hoped to engender was stifled.

The second effect is that externalities such as reputation, credibility or perceived trustworthiness are degraded. An example is when companies that outsource part of their supply chain face the devaluation of their own reputation when the behavior of their supplier is inappropriate, for example by committing child labor or human rights abuses. This has happened to many fashion companies, notably Nike whose partner in Cambodia was accused of using child labor. Similarly, the reputation of some of the major airlines, most of whom have entered into alliances with a variety of partners, some more respectable than others, risk devaluation if the standard of service of one or more of their partners is lower than their own. Delta Airlines, for example had an alliance with AeroPeru before it went bankrupt, as did Continental with Brazil's struggling VASP. Both South American firms had fatal accident rates many times higher than their American partners, and questions were raised in the press about what effect this was having on the American carriers' reputations (e.g. Woellert, 1998).

The paradox that emerges is one where resources or elements of catalytic resources that can be useful, and even essential, in some units may become hostile in others (Gander \& Rieple, 2002). Although the notion of resources traveling unintentionally across an organization's boundary into the partner is discussed by Lei and Slocum (1992), we suggest that the effect may be one of unintentional damage rather than, as they claim, unintentional value gain. This directs attention to how resources may be protected from contamination in this way.

\section{The role of institutional boundaries and boundary spanners}

We suggest that contamination occurs via two different, though interlinked, routes. The institutional boundaries of the firm may fail to reject inimical resources, and personnel running the alliance may fail to actively prevent inappropriate resources being accessed by, or transferred into, a partner. This may be the result of a stronger partner insisting on the adoption of a certain practice or the incorporation of a particular asset. Alternatively, a partner firm may fail to bound its practices during access-based collaboration; 'accidental' transfer occurs through individual employees taking up ideas, knowledge, attitudes and routines and introducing them, either consciously or unconsciously, into their working environment.

There are also two barriers to contamination; the institutional boundaries of the organizations, and the actions of alliance managers - boundary spanners. These are individuals who 'operate between the firm and the external environment' (Johlke, Stamper, \& Shoemaker, 2002: 116). They can be found in a number of roles: salespeople who interact with customers (Singh, Verbeke, \& Rhoads, 1996); managers of subsidiary divisions interacting with headquarters (Kostova \& Roth, 2003); as well as employees who manage a relationship with a separate organization (Perrone, Zaheer, \& McEvily, 2003). We use the term specifically to describe those individuals, often divisional managers but also functional experts such as marketers or designers, who liaise between the different organizations, coordinating access to 
valuable resources or transferring tacit and explicit knowledge (Aldrich \& Herker, 1977). One defining characteristic is that they are 'simultaneously exposed to competing expectations from their own and from partner organizations' (Perrone et al., 2003: 423). Boundary spanners and institutional boundaries are two inter-related and recursively dynamic aspects of resource co-ordination and may be conceptualized as actor and structure (Bhaskar, 1978; Giddens, 1984).

The institutional frontiers of an organization limit resource movement through physical distance and legal boundaries. But other important barriers are its cultural and ideological features. These are dynamic and capable of changing as the alliance develops over time. At the start, the conventions and beliefs embedded in working practices and decision-making routines differentiate an organization into its own 'domestic' approach and external 'foreign' approaches. Thus where new knowledge, working practices and objectives run counter to an organization's domestic conventions and beliefs, they may simply be ignored, not perceived as a possible resource or rejected as being deviant and too far from what the organization 'is' and 'does' (Cohen \& Levinthal, 1990). However, dynamic structuration processes mean that this sort of ideological difference may erode over time unless reproduced by actors who maintain the institutional barriers (Giddens, 1984). In making choices about which resources to transfer and which to retain, the boundary spanner (and those for whom they undertake the role), (re)constructs the boundary between the two organizations. Whether this is a conscious effort, played out by a skilled and reasoning individual, or an unconscious process, is a question for further research. However, we argue that the breaking down of these institutional barriers by unskilled or unthinking boundary spanners may have the unintended consequence of letting inimical resources damage the partner.

Boundary spanners are able to overcome resource hostility produced by ideological/institutional distance through their ability to understand the needs and resource deficiency/abundance of the two organizations, and translate these into benefits that both partners can understand. Their effectiveness is also mediated by trust, power and their location in social-capital-intensive networks that allow them access to privileged, often tacit, resources (Jones \& George, 1998). This access is preserved through their semi-detached location, both physical and ideological, so that they are only partially included in the firm (Pfeffer \& Salancik, 1978). Whether they are able to remain 'semi-detached' is particularly likely to be an issue in alliances where there is a formal power differential. For example where a larger company has an equity stake in a smaller one, the boundary spanner may experience pressures to impose the authority conferred by ownership (Blodgett, 1992). This may result in resources being transferred prematurely or otherwise inappropriately.

The transfer of tacit knowledge (Polanyi, 1967) is an important function of the boundary spanner. By definition tacit knowledge is unknown and expressed in the (unconscious) behaviors of individuals and groups of individuals. Boundary spanners gain knowledge from one domain and move it to be applied in another (Tushman \& Scanlan, 1981). This is an iterative process; the boundary spanner uses knowledge gained in the new environment to add to their own previous tacit knowledge which may then be moved back to the source unit and used in its enlarged form. Alternatively, they may elect to withhold the knowledge - potentially an important role for the boundary spanner in constructing and maintaining structural barriers between the partner organizations. The decision to retain or withhold knowledge may be either heedful or unconscious (although the former implies the recognition of tacit knowledge at an explicit, discursive level). As knowledge is an inherent part of the micro-culture that influences the effectiveness with which an resources are utilized (Rindova \& Fombrun, 1999), changes to an organization's knowledge store influence the schemata of its members, and hence the cognitive processes (Fiol, 1991) that influence its competency. Thus the accidental transfer of knowledge may have the effect of damaging a previously effective resource.

An understanding of the mechanisms of resource preservation and protection is important because firms entering alliances need to identify those resources that can and should be shared, and those whose 
value, if combined or transferred to the other firm, will decline. In the next section we focus on the popular recorded music industry, and use a Major music firm's relationships with its Independent partners to illustrate these concepts in practice.

\section{Resource Management in Recorded Music Industry Alliances}

As with other cultural/creative industries (Caves, 2000), the recorded music industry is characterized by numerous examples of alliances (Frith, 1988; Gander \& Rieple, 2002, 2004, Negus, 1992). All involve a combination of artistic talent, fad-influenced trends, complex operational capabilities, high-investment promotions, the union of creative and 'humdrum' business practices (Caves, 2000: 4) and products that 'embody some degree of intellectual property and convey symbolic meaning' (Throsby, 2001: 112).

To investigate these resource combinations across contrasting firm types, a case study approach was taken (Eisenhardt, 1989; Yin, 2003). This was deemed appropriate because we were seeking to investigate how resources are managed within alliances in the setting of the contemporary recorded music industry. The case examples that we have chosen thus exemplify a particular, or illustrative, way of operating in a specific setting. We do not claim that our findings are typical of other industries, or indeed are generalizable to any other population. In line with the principles of explanatory ethnography (Hammersley \& Atkinson, 1990), structuration theory (Giddens, 1984) and critical realism (Bhaskar, 1978), the most we will claim is that a similar combination of factors in other settings may have a tendency to result in similar outcomes.

Data were collected through interviews with 18 senior managers who were responsible for the management of relationships between a sub-division of a music industry Major (BigMusic), and seven of its Independent partners. The Independent partners had all established multiple album deals with BigMusic. In return for financial and operational support the Major acquired the right to market the Independent's output and receive a share of the revenue, a common alliance model within the sector (Hesmondhalgh, 1996). On average the alliance term was 5 years. As all four Majors have relationships with Independents, our exemplars typify the challenges of the resource contamination paradox; combining complementary yet potentially hostile resources. However, we have not investigated whether the manner in which our case study participants resolved this paradox is typical of the industry as a whole.

The Major's interviewees included the chief executive of the division and senior managers from the marketing, legal and business service functions. The interviews with the Independents were all carried out with the owner or managing director. As a condition of access full confidentiality was assured. Of the sample selected, one Independent refused to be interviewed and owing to contractual sensitivity we were denied permission to approach another. Interviews took place in the offices of the relevant organization, were semi-structured, lasted approximately 90 minutes and were tape-recorded and transcribed. Questions were designed to encourage reflection on the nature of the relationship with the partner and how specific relational activities were conducted.

\section{Resource partitions}

The recorded music industry contains two distinctly different firm types; the four Majors with a market share of around 70 per cent (IFPI, 2005), and smaller firms, the Independents, typically neither publicly 
owned nor owned by a global parent corporation. There is a bias within these firms towards one of two distinct sets of resources; those that support and enable the generation of new music, and those that exploit the outcome commercially: 'creative effort and humdrum commerce' (Caves, 2000: 4). Whilst activities and the firm types overlap, Independents' resources are typically focused on the creative effort that identifies and develops the music and artist(s), and Majors have the financial, promotional and distributional resources to exploit the music product (MBI World Report, 2002).

Some writers have characterized the relationship between the Majors and the Independents as hostile, with Majors preventing competition by allying with, and/or acquiring, rival firms (Gillett, 1996; Hesmondhalgh, 1996), in a manner that some studies into the production of culture have found to reduce product diversity (Dowd, 2004; Lopes, 1992; Peterson \& Berger, 1975). However, although there is overlap, where Independent firms use specialist Independent distribution companies, and the Majors use their existing network of A\&R offices, or label sub-divisions as 'listening posts' to identify and sign new talent (Hull, 2004) the resource advantages of each firm type appear significant, restricting the ability of one type to compete on the other's core terrain. Relationships between the two firm types are thus symbiotic, rather than competitive (Burnett, 1990; Frith, 1988; Throsby, 2002)— one reason why many Independents, on acquisition by a Major, appear to have been allowed to retain some autonomy (Huygens, Baden-Fuller, Van Den Bosch, \& Volberda, 2001).

The Independents' creative-effort resources fall into three categories: the knowledge and insight to identify which among many emerging trends will gain wider social acceptance, and which artist(s) among a host of false positives will become a successful (commercial and artistic) representative of that trend; the ability to be seen by the future artist(s) as an organization that will value their work and look after their interests; and the skills and know-how to encourage the artist(s) to develop their music into a commercially viable product.

The knowledge required to identify new 'talent', from among the hundreds of speculative samples that record companies are sent each week (Passman, 1994) or the thousands of live music events, is a function of the individual or firm's presence within a network of contacts and social groups (Jones \& Hesterly, 1997). Information about artist(s), and the reaction to their music, is gained and transferred in a highly socialized environment (Caves, 2000), access to which is limited by behavioral and ideological barriers such as vocabulary and an unambiguous non-membership of mainstream groups. As the Majors are seen as mainstream they are locked out of this information-sharing environment. As one of BigMusic's boundary spanners said:

'there was this whole movement of bands and music, but obviously the Major record companies didn't really have a slice of it and didn't really have any impact on it. . .because ... it wasn't what they were interested in you know?.. It was three men and an amp making music somewhere'

Similarly, in order to secure the contractual signature of the musician(s) an organization needs credibility and a reputation attractive to those with artistic sensibilities. The role of trust is critical, the more so because early in their career artists have little experience to draw on when making decisions involving signing-on fees and royalty payments. Antipathy between artists and the Majors (Hesmondhalgh, 1998), tends to make Independents more successful at winning the trust of unsigned talent.

Finally, the firm needs to nurture the musical development of the artist(s), ensuring that the end result has both cultural and commercial value. This requires an appreciation of the non-linear creative process and an ability to create a protected environment within which the artist(s) can develop, requiring an informal context and a value system which privileges esthetic and creative discourse, typically found in the Independents.

Resources that enable the exploitation of musical products tend to be found in the Major: marketing planning capabilities, where budgeted and scheduled plans are created, operationalized and monitored; 
distributional capabilities that are dependent on contacts in different countries and an appreciation of different market demands and tastes; procedures required to process, supply and monitor sales over a widespread area; advantages brought about by scale, such as the ability to secure access to main retailers' stores and to encourage the product being played on radio stations; and finally, promotional resources such as producing coordinated public relations and campaigns to secure publicity across a variety of media in different countries. Described by one Major employee as a 'huge apparatus' for international distribution and promotion, these arise from scale and scope economies and are difficult for the smaller, more narrowly focused Independents to attain.

The recorded popular music industry is thus partitioned (Carroll, 1985; Mezias \& Mezias, 2000): a few large generalist firms have high market shares and smaller specialist firms exploit those resources not accessed by (or accessible by) the Majors. Thus, an Independent manager claimed:

'there is no middle ground. You are either a major player, or a small little independent'

The Major's promotional, distributional and managerial resources and routines can be used for a boy band or an established soul singer, while the Independent's creative resources and routines, which includes its reputation as well as knowledge, are commonly restricted to certain genres of music. From Elvis Presley to Britney Spears the role of the Independents (Sun and Zomba, respectively) in identifying, signing and developing new talent while their respective Majors (RCA and BMG) provide the promotional and distribution resources, is an enduring theme. To use a cellular analogy, the persistence of this type of arrangement appears to be achieved by taking only selected resources through a semi-permeable membrane, the firm's boundary, a structure which acts to maintain the firm's distinctiveness.

\section{The role of the semi-permeable boundary}

Firms are open systems (Katz \& Kahn, 1978) yet require some form of boundary between themselves and the environment and their partners in order to build and co-ordinate resources. The same is true for cells that use a semi-permeable membrane to achieve this open but bounded status. Thus the firm is surrounded by a selectively permeable boundary that allows it to accept certain resources yet reject others, and in so doing preserve the specialisms that are embodied in their resources and routines. Firms are as much what they choose not to do as what they do (Drucker, 1955).

Using this analogy we can consider how this boundary is constituted from a combination of ideological, geographical and legal constructions. Contracts with external firms such as suppliers, partners and buyers ensure that exchanges are made while protecting the resources, or the benefits of such resources, from appropriation or unfair use. Geographical location also acts as a selective membrane. In cases where parties are separated physically, certain resources such as tacit knowledge will be prevented from being transferred or accessed, unlike other more explicit knowledge such as the appropriate person to contact in a new geographic market or information on consumers and retailers in different countries.

Another defining element to the barrier drawn between the firm and its partners and environment comes from its ideological and normative positions. These institutional barriers (Parsons, 1951; Selznick, 1957) knowingly (in the form of the reasoning processes of the sentient individuals in the firms) and unknowingly (in the form of sub-rational structures such as ideologies) reject activities and routines that do not align with currently held paradigms (Kiesler \& Sproull, 1982). Resources to which these rejected activities are essential are thus kept out. For the Independent this might involve the rejection of knowledge and attitudes required to maximize sales of their artists, such as: building 
relationships with major retailers; the formation of relationships with other Independent labels to provide a wider and less genre-specific roster; establishing reporting standards with foreign distributors in order to monitor sales closely; and a search for finance from outside the Majors, say from banks and venture capitalists. For the Major these barriers may lead to the bypassing of new talent that does not obviously fit with its existing roster, yet is the start of an emerging music trend, or the alienation of artists through contractual inflexibility and an inability to create a supportive environment. This results in the occasional highly embarrassing incident, such as the failure to sign The Beatles at the early stage of their career or retain U2 after their first album. As an Independent manager said:

'They have become extremely formatted in terms of dealing with things. When they have a band that doesn't fall into any format... they get lost, you know.'

The presence of these institutional barriers, alongside the persistence of collaborations between Major and Independent, suggests that there exists a certain inimicality between firm types; where some resources cannot be successfully employed by firms that simultaneously hold certain other resources. This is particularly true in the case of those catalytic resources that are used in the 'creative effort' by the Independent. The reputation, knowledge and routines that support this activity are all linked to participation in networks and discourses that are characterized by a 'not like a Major' attitude, a 'them and us' discourse frequently evident during the interviews.

One of the best known Independent owners in the UK, Alan McGee, launched a new label with the intention of 'going back underground' to wage guerrilla war on 'corporate fat cats'... the aim being 'to create an alternative universe' (Lester, 2000: 18). Similarly, one of our interviewees used the Star Trek characters the 'Borg' to refer to the Majors (the Borg are an ant-like communal species with no individuality, whose driving force is to assimilate other species in order to capture their knowledge). A fierce desire to remain different was also apparent in other interviews with Independent managers. One compared the situation to that of the Asterix comic where a huge Roman empire surrounds one tiny French village. The names of the Independent labels frequently signal this difference with names that symbolize their status, attitude and feelings. Examples include '1-OFF Recordings', 'In Jeopardy Records', 'Outcaste Records', 'Better the devil records', 'Are we mad?', 'Global Underground', 'Creation', 'Attitude' and 'Naïve'.

The Major in our study was also aware of the need to maintain its separateness. Concern over the potential devaluation of the resources of a partner was evident in an earlier strategic alliance between BigMusic and an Independent. When an option to buy a controlling share of the Independent fell due, the Major did not take the option up, preferring instead to pay the label's owners to extend the agreement on the same, independence-retaining, terms by another 5 years.

The semi-permeable boundary's function is thus to prevent certain practices and routines being adopted in order to preserve the advantages of specialization, and only allow the transfer of resources that are beneficial to the organization. As one of BigMusic's boundary spanners explained:

'We left them intact... 'cause obviously if you destroy the infrastructure you destroy the ground on which all of this grows'.

Our interview data contained numerous other references to this principle. One Independent manager described a conversation that he had had with a label manager from BigMusic:

'And (BigMusic manager) said "people like you who are difficult to manage. . . it is a shame because we need people like you, but it is very difficult to find a place in our organization (for you)" ... and that is very true... the Independents I have met are very individual people, some of them are quite 
arrogant, some of them have big egos, some of them are just creative, mad people. It is difficult to put them in a structure because they don't react to the same reasons (sic)'.

However, while specialization brings advantages there exist some resource sets that are complementary and, if combined through an alliance, will produce a more successful outcome than would have been achieved independently. When managing/structuring these alliances two factors need to be considered: first how to overcome the institutional boundary in order to combine the different knowledge and intangible resources of the two firms; and, second, how to ensure that in doing so existing resources are not degraded by hostile features of the partner's resources. The first consideration is important as unless the firms reconfigure their boundaries, elements of the resources deployed will be rejected by the institutional membrane and thus produce a suboptimal outcome. The second is also important because, if the boundary can be reconfigured, there is a concomitant danger of damaging the resources through contact with hostile elements of the firm's own resources.

These observations illustrate the importance of our resource preservation perspective. In the music industry and other sectors of the cultural economy that involve the union of creative effort with formalized/routinized business practices, these mechanisms appear especially important to alliance success.

\section{The role and attributes of the boundary spanner}

In our sample of firms the individuals whose activities involved boundary spanning practices and roles were three managers from the Major (BigMusic) and key individuals in the Independents, sometimes the owners, sometimes managers. BigMusic's boundary spanners had a managerial function within a separate division of BigMusic and were involved in identifying Independents and their artists, and then constructing the funding arrangements, communication procedures and marketing and distribution plans for the alliance. The Independent interviewees for their part liaised with BigMusic's boundary spanners during the setting up and maintenance of the alliance.

In the popular recorded music industry, musical trends can quickly emerge and consumer tastes rapidly change. Driven by the key cultural imperative, 'the expression of difference' (Garnham, 1987: 58), trends come and go making the investment decision difficult and the outcome uncertain (Hirsch, 1972). Shifts in markets can rapidly devalue the resources of a firm and increase the value of another's. For example in the late 70s Disco suddenly lost favor and the Majors were left with large numbers of artists whose value diminished, and an artist and repertoire function that was inappropriately focused on the identification of new disco acts. However those smaller (Independent) firms that were networked into the emerging Punk scene experienced an increase in the value of their knowledge and skills and assets.

Both firms needed boundary spanners to manage the transfer and access to their complementary resources: creative production (Independent) and exploitation (Major). The Major's boundary spanners needed to identify new talent and if already signed, construct alliances with the Independents that managed them. Their ability to do this is related to their partial inclusion within the firm (Pfeffer \& Salancik, 1978), by being part of a network of social and cultural ties that allows access to privileged knowledge and confers credibility through membership. This allows the boundary spanner to overcome institutional constraints and recognize new artist(s)/music movements and also to secure the signature of any identified artist. BigMusic's boundary spanners were either ex (non-mainstream)-musicians or former heads of Independent labels. This allowed them access to artists and music scenes and gave them the critical credibility needed to inspire trust in the Independent personnel (Bourdieu, 1993). BigMusic's boundary spanners worked in a separate division, which itself signaled its identity as 
different from the rest of the corporation. They were described in terms that identified them as sharing the Independent worldview.

'He has a bit of an Indie head about him.', '. . .he's mad!' (admiringly), '. . .he's sort of up there in our corner' and 'it's nice to know they have come from an interesting background, they made music because they wanted to.'

Thus we suggest that boundary spanners are more likely to be effective if they possess what are perceived to be common attitudes and values by personnel from both partner firms. This congruence can be reinforced or authenticated by demonstrating similar experience, and by being able to adapt their language and communication style to fit the prototypical discourses of both firms. This ability is more critical when the cultural difference between the firms is greatest.

The Independent's boundary spanners have similar access to reputational capital, but they also needed to overcome any resistance to partnering a Major, and reassure their artists and network peers that this did not mean they were 'selling out'. Several interviewees spoke of the initial nervousness and worry on the part of their artists that required careful explanation and reassurance.

'... they know I am not going to sell them to (Big Music) or anything. ...partly because (Big Music boundary spanner) is someone they know and trust.' and 'you can only be involved with them (artists) when they trust your judgment'.

We found many examples of the importance attached by the Major's boundary spanners to their reputation for artistic sensitivity. Although ostensibly members of a larger, more powerful, organization, they were careful to justify themselves with statements such as 'we are credible because we proved it' (BigMusic) and 'people know me' (BigMusic). In order to maintain their reputation within the Independent community, when BigMusic's relationship with an Independent ended, its boundary spanners pushed it to waive its right to acquire some of the back catalogue.

We suggest that there is risk in collaborating with firms whose resources are particularly sensitive to devaluation by other resource sets:

'...the fear was that you would take over these companies, turn them in to BigMusic companies, which was not what was required. . to break their nature, to change the nature of the Independent companies was going to destroy them'.

Thus the boundary spanner's task is to allow the Independent access to the commercial resources of the Major without them (or resource particles) leaking back to the Independent to damage its reputation, music-creation routines, and socially networked knowledge. The boundary spanner constructs aspects of separateness, protecting necessary differences. The phrase 'hands off' was used a number of times by Independents to describe BigMusic's boundary spanners' stance. Interviewees frequently distinguished this from their experience of other Majors, using for example, the often repeated anecdote of the executive suggesting, during a visit to the recording studio, that the snare drum should be turned up. He was told to turn a knob, did and then remarked that it sounded much better. The knob was a dummy and had had no effect on the sound. This type of interference was absent in BigMusic's relationships with its Independents, with its boundary spanners claiming that they stayed 'well away from that (side of things)'. One Independent suggested that this was 'why they had had such phenomenal success'.

Another account demonstrates the importance of mediated separation of creative activities from the commercial. One of BigMusic's long-standing Independent partners had obtained a sample music track from an unsigned band, which was not representative of the firm's roster or identity, yet appeared to 
them to have commercial value. They offered it to BigMusic, asking if they wanted to release it on their own label. The response was a strong 'no' with the explanation that this was not what the relationship was about - the Independent was supposed to create music they would be proud of. The Independent was pleased by this response, and interpreted this as a re-affirmation of the importance of their separateness and difference. However, we also note that in this example there is also the possibility for resource particles, in the form of beliefs as to the commercial value of some types of music product, to cross firm boundaries.

A further illustration is found in the funding of Independents. BigMusic has business-planning skills that are of benefit to Independents, but which simultaneously need to be managed in such a way that allows their creative routines to be preserved. A frequent theme that emerged from the interviews was the need to reduce the funding and sales' targets commonly set by other Majors. Both partners' boundary spanners worked together to ensure that BigMusic's planning and funding arrangements were tailored to suit the Independent's artists and personnel. For example by not giving large advances at an early stage in the artist's career, in contrast to other Majors, they allowed them time and space to develop their music.

BigMusic and the Independent's boundary spanners simultaneously acted to protect the bounded independence of the Independent partner. Communication with senior levels of BigMusic's hierarchy was undertaken only by the Independent's boundary spanners who had to comply with reporting standards required for budget requests. With the creation of artistic products being so uncertain and at times lengthy, the ability of BigMusic's boundary spanners to defend their partners' output using both financial and artistic arguments was vital and difficult (Bourdieu, 1993). As one said, 'I had to fight for it in New York'. (BigMusic's headquarters). This allowed the Independent's artists to feel that they were not working for a multinational corporation One Independent interviewee explained:

'I think most bands, like, their nightmare is to play a show in London and they go back. They've been on stage. Done a great gig. Very tired, probably very drunk. . I don't know. Go backstage and there's

like 15 suits sitting in the dressing room going "Congratulations" and they don't even know who they are, you know?'.

This leads us to suggest that the 'highly improbable... and rarely achieved' (Bourdieu, 1993: 76) capacity to combine potentially inimical features, in this case esthetic and commercial interests, without sacrificing the ability to achieve either, is the feature of an effective boundary spanner in this industry. It is the aptitude to mediate the selective access to resources that prevents the contamination of the resource sets of each partner whilst allowing them to benefit from their operation. Those boundary spanners we observed within the music industry that were attempting to manage this paradox we describe as 'Janusian' (Sjöstrand, 1997), on account of their ability to face both organizations simultaneously.

\section{Implications for Further Research}

A number of implications for research arise from this discussion. Although work has been undertaken in industries which share similar characteristics to the music industry, such as film and television programming (DeFillippi \& Arthur, 1998; Jones, 2001; Mezias \& Mezias, 2000; Miller \& Shamsie, 1996; Robins, 1993; Storper, 1989) and which are similarly dependent on new ideas and fashion-driven genres, the recorded music industry is a relatively neglected yet promising sector for research. Here, we highlight key areas which we believe warrant further attention. 
This paper's introduction of a resource preservation perspective to sit alongside current debates on resource transfer and access, such as those relating to stickiness, learning races, leakage, and appropriation, provides an additional means of assessing the factors behind successful or unsuccessful collaborations. Further research is needed on the way in which both institutional and individual (boundary spanners) barriers moderate the flow of different types of resources (physical and knowledge-based) and how different types of resources and resource particles, especially those that cannot be brought to a discursive level, present different challenges for the boundary spanner. Other promising lines for research concern the effect of the alliance structure on the boundary spanner's role, for example, whether administrative fiat and equity asymmetry interfere with the construction and maintenance of the institutional boundary and the selection of resources to be protected.

The role of trust in the effective working of boundary spanners and alliance operations suggests a paradox that is hinted at but not fully investigated in this study: that trust may actually increase the possibility of contamination. If boundary spanners are especially trusted, previously rejected working practices or beliefs from their organization may be viewed in a more positive light. Preventing this would require awareness of this danger and the active construction of barriers to resource transfer. Thus the relationship between trust levels and contamination would appear to be an interesting avenue for research particularly where very different resource sets are found, such as between product creation and exploitation in the film, design, and publishing industries.

An interesting question is whether our conceptualization of the role of boundaries and boundary spanners and the problems of resource preservation and contamination, applies in other firms within the music industry, let alone in other industries. The shared set of priorities and behaviors found amongst the boundary spanners from BigMusic and its Independent partners suggests that the 'protected union' of resources during collaboration may be a field-wide practice that has been institutionalized through repetition and reciprocation (Berger \& Luckmann, 1967), although there are clearly some differences between BigMusic's policies and those of other Majors. Likewise, the manner in which changes in such practices are disseminated within the field would constitute a useful extension to knowledge of processes of institutionalization.

The extension of research into resource contamination that this paper calls for applies equally to resource management within firms, between a parent and a strategic business unit or semi-autonomous department. In the music industry this would involve a study of the relationship between the Majors and the Independents they have acquired, and that have not been fully integrated into the parent company's hierarchy. Although many of these issues have long been discussed within the new venture division literature (e.g. Block \& MacMillan, 1993; Burgelman \& Sayles, 1986; Kanter, 1985), the precise role of the boundary spanner in the protection from contamination of innovative resources has not previously been examined. In the case of semi-autonomous divisions, as opposed to alliances with an independent partner, we speculate that the possibility of contamination through inappropriate resource transfer is likely to be higher; institutional conventions become weakened by the sense of ownership and the division's exposure to action by administrative fiat increases by virtue of being part of the Major's hierarchy.

\section{Conclusion}

Our study has revealed a paradox at the heart of the management of the union of humdrum and creative resources in the popular recorded music industry; that of complementary yet hostile resources. Resolving this problem requires the use of resource preserving mechanisms; the organization's institutional barriers and the alliance's boundary spanners, to manage the access to and transfer of 
resources without toxic elements being assimilated in the receiving firm and contaminating the functioning of its existing resources.

Many of the writers who have discussed the benefits of strategic alliances and networked structures in industries such as software, pharmaceuticals and biosciences (e.g. Barley, Freeman, \& Hybels, 1992; Liebeskind, Oliver, Zucker, \& Brewer, 1996; Powell, Koput, \& Smith-Doerr, 1996), have identified the ways in which such collaborations allow firms to focus on what they do best. However, although the problem of power asymmetry and learning races, and thus resource loss, has been discussed in this literature, there has been almost no attention paid to how partner firms recognize and deal with the unintentional contamination and degradation of their partner's resources by their own. This possibility suggests that those responsible for the management of alliances should be as much concerned about the need to protect their, and their partner's, resources from contamination as the possibility of a partner appropriating key resources for their private benefit. In order to protect the value of the alliance relationship, firms both need to be able to identify those resources that can and should be shared, and those whose value if combined or transferred will decline. Looked at this way, collaborating firms are involved in managing parallel and simultaneous processes of transferring, accessing and allowing access to certain resources; protecting other resources from appropriation; and preventing other, hostile resources from unintentional contamination or combination.

Boundary spanners play a critical role in managing this paradox by both blocking and providing access to resources by means of moving between the two domains, both physically but also metaphorically. They act as the mechanism for transferring certain types of resource, of which tacit knowledge is an important example. They can only do this because they possess certain attributes such as beliefs and values that allow them to 'face' both firms ideologically, in a Janusian manner. They are also 'bilingual' in the language of both sides and can switch the way they present themselves as needed. This does not imply deceit, rather that successful boundary spanners can concurrently 'buy in' to competing perspectives (Bourdieu, 1993; Sjöstrand, 1997). That this is not a superficial or calculative 'mask-swapping' activity is shown by the importance of credibility and trustworthiness to their relationships, and the constant scrutiny placed on their attitude and behavior by their own firm, their partner boundary spanners and their wider social network.

Firms can benefit from such individuals who are both members and participants in their own organizational community and also 'plugged' into a wider social network that allows privileged access to critical and, hard-to-obtain, industry knowledge (Burt, 1992). This partially located position enables these individuals to span ideological fields and in so doing overcome any barriers that may prevent the organization from obtaining the new resources that it needs. In the music industry it appears that they needed to actively maintain this semi-detached position if it was itself not to become corrupted and damaged.

Though certain resources (such as creativity-development routines or reputation) have context-specific characteristics that make transferring them into another environment problematic, elements of these situational or catalytic resources, which we have termed resource particles, can be transferred to the partner firm and degrade the value of their existing idiosyncratic resources. Boundary spanners, and the institutional frontiers they help to construct, thus play a critical role in reconciling the inherent paradox in music industry alliances: the combination of complementary yet hostile resources.

\section{Acknowledgements}

In addition to the constructive comments of this journal's anonymous reviewers, we would like to acknowledge the contributions of Professor Robert Grant, for his observations on an earlier draft, and of 
Bob DeFillippi, whose suggestions have greatly helped us in sharpening the arguments set out in this paper.

\section{Author biographies}

Jonathan Gander is Senior Lecturer in Strategic Management at the University of East London. His research interests lie in the production of popular culture, and the relationship between geography and organizational behavior.

Adrian Haberberg is Senior Lecturer in Strategic Management and Director of MBA Programmes at the Westminster Business School, University of Westminster. Dr Haberberg's research interests relate to strategic decision-making and the mechanisms whereby strategies diffuse within and between organizations. He is co-author (with Alison Rieple) of The Strategic Management of Organisations. Alison Rieple is Professor of Strategic Management and Director of Research at Harrow Business School, University of Westminster. Professor Rieple's research interests focus on the management of design, the structuring of innovation and the micro-politics of change. She is a member of the Design Management Institute's Academic Council.

\section{References}

Aldrich, H., \& Herker, D. (1977). Boundary spanning roles and organization structure. Academy of Management Review, 2, 217-230.

Amit, R., \& Schoemaker, P. (1993). Strategic assets and organizational rent. Strategic Management Journal, 14, $33-46$.

Bacharach, S., \& Lawler, E. (1980). Power and politics in organizations. San Francisco, CA: Jossey Bass.

Baden-Fuller, C., Hunt, B., \& Calori, R. (1995). Novotel case study. Lyon, France: Groupe ESC.

Balakrishnan, S., \& Koza, M. (1993). Information asymmetry, adverse selection and joint ventures: Theory and evidence. Journal of Economic Behavior and Organization, 20, 99-117.

Barley, S., \& Tolbert, P. (1997). Institutionalization and structuration: Studying the links between action and institution. Organization Studies, 18, 93-117.

Barley, S., Freeman, J., \& Hybels, R. (1992). Strategic alliances in commercial biotechnology. In N. Nohria, \& R. Eccles (Eds.), Networks and organizations: Structure, form, and action (pp. 331-347). Cambridge, MA: Harvard Business School Press.

Barney, J. (1991). Firm resources and sustained competitive advantage. Journal of Management, 17, 99-121.

Bhaskar, R. (1978). A realist theory of science. Sussex: Harvester Press.

Berger, P., \& Luckmann, T. (1967). The social construction of reality. Harmondsworth: Penguin.

Block, Z., \& Macmillan, I. (1993). Corporate venturing: Creating new businesses within the firm. Cambridge, MA: Harvard Business School Press.

Blodgett, L. (1992). Factors in the instability of international joint ventures: An event history analysis. Strategic Management Journal, 13, 475-481.

Borys, B., \& Jemison, D. (1989). Hybrid arrangements as strategic alliances: Theoretical issues in organizational combinations. Academy of Management Review, 14, 234-249.

Bourdieu, P. (1993). The field of cultural production. Cambridge, UK: Polity Press.

Burgelman, R., \& Sayles, L. (1986). Inside corporate innovation. New York: Free Press.

Burns, T., \& Stalker, G. (1961). The management of innovation. London: Tavistock Publications.

Burnett, R. (1990). Concentration and diversity in the international phonogram industry. Gothenburg: Gothenburg University Press. 
Burt, R. (1992). The social structure of competition. In N. Nohria, \& R. Eccles (Eds.), Networks and organizations: Structure, form, and action (pp. 57-91). Cambridge, MA: Harvard University Press.

Campbell, A., Goold, M., \& Alexander, M. (1995). Corporate Strategy: The quest for parenting advantage. Harvard Business Review, 73, 120-132.

Carroll, G. (1985). Concentration and specialization: Dynamics of niche width in populations of organizations. American Journal of Sociology, 90, 1263-1283.

Caves, R. (2000). Creative industries. Cambridge, MA: Harvard University Press.

Cohen, W., \& Levinthal, S. (1990). Absorptive capacity: A new perspective on learning and innovation. Administrative Science Quarterly, 35, 128-152.

Das, T. K., \& Teng, B.-S. (2000a). A resource-based theory of strategic alliances. Journal of Management, 26, 31-61.

Das, T. K., \& Teng, B.-S. (2000b). Instabilities of strategic alliances: An internal tensions perspective. Organization Science, 11, 77-101.

DeFillippi, R., \& Arthur, M. (1998). Paradox in project-based enterprise: The case of film making. California Management Review, 40, 125-139.

Dowd, T. (2004). Concentration and diversity revisited: Production logics and the U.S. mainstream recording market, 1940-1990. Social Forces, 82, 1411-1455.

Drucker, P. (1955). The practice of management. London: Heinemann.

Eisenhardt, K. (1989). Building theories from case study research. Academy of Management Review, 14, 532-550.

Emirbayer, M. (1997). Manifesto for a relational sociology. American Journal of Sociology, 103, 281-317.

Faulkner, D. (1995). International strategic alliances. London: McGraw-Hill.

Fiol, C. (1991). Managing culture as a competitive resource: An identity based view of sustainable competitive advantage. Journal of Management, 17, 191-211.

Frith, S. (Ed.). (1988). Facing the music: Essays on pop, rock and culture. London: Mandarin.

Gander, J., \& Rieple, A. (2002). Inter-organisational relationships in the worldwide popular recorded music industry. Creativity and Innovation Management, 11, 248-254.

Gander, J., \& Rieple, A. (2004). How relevant is transaction cost economics to inter-firm relationships in the music industry? Journal of Cultural Economics, 28, 57-79.

Garnham, N. (1987). Concepts of culture-public policy and the cultural industries. Cultural Studies, 1, 54-61.

Giddens, A. (1984). The constitution of society: Outline of the theory of structuration. Cambridge, UK: Polity Press.

Gill, J., \& Butler, R. (2003). Managing instability in cross-cultural alliances. Long Range Planning, 36, $543-548$.

Gillett, C. (1996). The sound of the city. London: Souvenir Press.

Gioia, D., \& Poole, P. (1984). Scripts in organizational behavior. Academy of Management Review, 9, 449-459.

Granovetter, M. (1985). Economic action and social structure: A theory of embeddedness. American Journal of Sociology, 91, 481-510.

Grant, R., \& Baden-Fuller, C. (1995). A knowledge-based theory of inter-firm collaboration. Academy of Management Best Paper Proceedings, 17-21.

Grant, R., \& Baden-Fuller, C. (2004). A knowledge accessing theory of strategic alliances. Journal of Management Studies, 41, 61-84.

Hamel, G. (1991). Competition for competence and inter-partner learning within international strategic alliances. Strategic Management Journal, 12, 83-103.

Hammersley, M., \& Atkinson, P. (1990). Ethnography. London: Routledge.

Harrigan, K., \& Newman, W. (1990). Bases of inter-organizational co-operation: Propensity, power and persistence. Journal of Management Studies, 27, 417-434.

Helfat, C., \& Peteraf, M. (2003). The dynamic resource-based view: Capability lifecycles. Strategic Management Journal, 24, 997-1010.

Hennart, J., Roehl, T., \& Zietlow, D. (1999). Trojan horse or workhorse? The evolution of U.S.-Japanese joint ventures in the United States. Strategic Management Journal, 20, 15-29.

Hesmondhalgh, D. (1996). Flexibility, post-fordism and the music industries. Media, Culture and Society, 18, 469-488.

Hesmondhalgh, D. (1998). The British dance music industry: A case study of independent cultural production. British Journal of Sociology, 49, 234-251.

Hill, C., \& Jones, G. (2001). Strategic management: An integrated approach. Boston, MA: Houghton Mifflin.

Hirsch, P. M. (1972). Processing fads and fashions: An organization-set analysis of cultural industry systems. American Journal of Sociology, 77, 639-659.

Hull, G. (2004). The recording industry (2nd ed.). New York, NY: Routledge. 
Huygens, M., Baden-Fuller, C., Van Den Bosch, F. A. J., \& Volberda, H. W. (2001). Co-evolution of firm capabilities and industry competition: Investigating the music industry. Organization Studies, 22, 971-1011.

Inkpen, A., \& Beamish, P. (1997). Knowledge, bargaining power and the instability of international joint ventures. Academy of Management Review, 22, 177-202.

International Federation of the Phonographic Industries. (2005). The recording industry in numbers. London: IFPI.

Johlke, M., Stamper, C., \& Shoemaker, M. (2002). Antecedents to boundary spanner perceived organizational support. Journal of Managerial Psychology, 17, 116-128.

Jones, C., \& Hesterly, W. (1997). A general theory of network governance: Exchange conditions and social mechanisms. Academy of Management Review, 22, 911-945.

Jones, C. (2001). Co-evolution of entrepreneurial careers, institutional rules and competitive dynamics in American film, 1895-1920. Organizational Studies, 22, 911-944.

Jones, G., \& George, J. (1998). The experience and evolution of trust: Implications for cooperation and teamwork. Academy of Management Review, 23, 531-546.

Kale, P., Singh, H., \& Perlmutter, H. (2000). Learning and protection of proprietary assets in strategic alliances: Building relational capital. Strategic Management Journal, 21, 217-238.

Kanter, R. (1985). Supporting innovation and venture development in established companies. Journal of Business Venturing, 1, 47-60.

Katz, D., \& Kahn, R. (1978). The social psychology of organization (2nd ed.). New York, NY: John Wiley and Sons.

Kiesler, S., \& Sproull, L. (1982). Managerial responses to changing environments: Perspectives on problem sensing from social cognition. Administrative Science Quarterly, 27, 548-570.

Kostova, T., \& Roth, K. (2003). Social capital in multinational corporations and a micro-macro model of its formation. Academy of Management Review, 28, 297-317.

Lei, D., \& Slocum, J. (1991). Global strategic alliances: Payoffs and pitfalls. Organizational Dynamics, 19 , 44-62.

Lei, D., \& Slocum, J. (1992). Global strategy, competence-building and strategic alliances. California Management Review, 35, 81-97.

Lester, P. (2000). Barmy army: Alan McGee has gone back underground with a new label to wage war on the corporate fat cats. But he's not going to get very far with this lot. The Guardian (8th September).

Liebeskind, J., Oliver, A., Zucker, L., \& Brewer, M. (1996). Social networks, learning, and flexibility: Sourcing scientific knowledge in new biotechnology firms. Organization Science, 7, 428-443.

Lopes, P. (1992). Innovation and diversity in the popular music industry, 1969 to 1990. American Sociological Review, 57, 56-71.

McEvily, B., \& Marcus, A. (2005). Embedded ties and the acquisition of competitive capabilities. Strategic Management Journal, 26, 1033-1055.

Mezias, J., \& Mezias, S. (2000). Resource partitioning; the founding of specialist firms, and innovation: The American feature film industry, 1912-1929. Organization Science, 11, 306-322.

Miller, D., \& Shamsie, J. (1996). The resource-based view of the firm in two environments: The Hollywood film studios from 1936-1965. Academy of Management Journal, 39, 519-543.

Mowery, D., Oxley, J., \& Silverman, B. (1996). Strategic alliances and interim knowledge transfer. Strategic Management Journal, 17, 77-91.

Music Business International (MBI). (2002). World report. London: CMP.

Negus, K. (1992). Producing pop: Culture and conflict in the popular music industry. London: Arnold.

Nelson, R., \& Winter, S. (1982). An evolutionary theory of economic change. Cambridge, MA: Belknap Press.

Parsons, T. (1951). The social system. New York, NY: Free Press.

Passman, D. (1994). All you need to know about the music business. New York, NY: Simon \& Schuster.

Penrose, E. (1959). The theory of the growth of the firm. Oxford: Blackwell.

Perrone, V., Zaheer, A., \& McEvily, B. (2003). Free to be trusted? Organizational constraints on trust in boundary spanners. Organization Science, 14, 422-439.

Peteraf, M., \& Barney, J. (2003). Unraveling the resource-based tangle. Managerial and Decision Economics, 24, 309-323.

Peterson, R., \& Berger, D. (1975). Cycles of symbol production: The case of popular music. American Sociological Review, 42, 158-173.

Pfeffer, J., \& Salancik, G. (1978). The external control of organizations: A resource dependence perspective. New York, NY: Harper \& Row.

Polanyi, M. (1967). The tacit dimension. New York, NY: Ancor.

Porter, M., \& Fuller, M. (1986). Coalitions and global strategy. In M. Porter (Ed.), Competition in global industries (pp. 315-344). Cambridge, MA: Harvard University Press. 
Powell, W. (1987). Hybrid organizational arrangements: New form or transitional development? California Management Review, 30, 67-87.

Powell, W., Koput, K., \& Smith-Doerr, L. (1996). Interorganizational collaboration and the locus of innovation: Networks of learning in biotechnology. Administrative Science Quarterly, 41, 116-145.

Reed, R., \& DeFillipi, R. (1990). Causal ambiguity, barriers to imitation, and sustainable competitive advantage. Academy of Management Review, 15, 88-102.

Rindova, V. P., \& Fombrun, C. J. (1999). Constructing competitive advantage: The role of firm-constituent interactions. Strategic Management Journal, 20, 691-710.

Robins, J. (1993). Organization as strategy: Restructuring production in the film industry. Strategic Management Journal, 14, 103-118.

Selznick, P. (1957). Leadership in administration. New York, NY: Harper \& Row.

Senge, P. (1992). Building learning organizations. The Journal for Quality and Participation, 15, 30-38.

Simon, M., Houghton, M., \& Gurney, J. (1999). Succeeding at internal corporate venturing: roles needed to balance autonomy and control. Journal of Applied Management Studies, 8, 145-159.

Singh, J., Verbeke, W., \& Rhoads, G. (1996). Do organizational practices matter in role process? A study of direct and moderating effects for market-orientated boundary spanners. Journal of Marketing, 60, 69-86.

Sjöstrand, S. (1997). The two faces of management. London: International Thompson Business Press.

Spekman, R., Forbes, T., Isabella, L., \& Macavoy, T. (1998). Alliance management: A view from the past and a look to the future. Journal of Management Studies, 35, 747-772.

Spender, J. (1996). Making knowledge the basis of a dynamic theory of the firm. Strategic Management Journal Winter, Special issue, 17, 5-62.

Storper, M. (1989). The transition to flexible specialization in the US film industry: External economies, the division of labor, and the crossing of industrial divides. Cambridge Journal of Economics, 13, 273-305.

Storper, M. (1997). The regional world. New York, NY: Guildford Press.

Throsby, D. (2001). Economics and culture. Cambridge: Cambridge University Press.

Throsby, D. (2002). The music industry in the new millennium: Global and local perspectives. Paris: UNESCO.

Tushman, M., \& Scanlan, T. (1981). Characteristics and external orientations of boundary spanning individuals. Academy of Management Journal, 24, 83-98.

Venkatraman, N., \& Subramanian, M. (2002). Theorising the future of strategy: Questions for shaping strategy research in the knowledge economy. In A. Pettigrew, H. Thomas, \& R. Whittington (Eds.), Handbook of strategy and management (pp. 461-474). London: Sage.

Von Hippel, E. (1994). 'Sticky information' and the locus of problem solving: Implications for innovation. Management Science, 40, 429-439.

Wernerfelt, B. (1984). A resource-based view of the firm. Strategic Management Journal, 5, 171-180.

Woellert, L. (1998). U.S. airlines: Make sure your partners are safe. Business Week (19th October, 3600 ), 132. Yin, R. (2003). Case study research: Design and methods (3rd ed.). Thousand Oaks, CA: Sage Publications. 